\title{
FOREWORD
}

\section{Biodiversity: Brazil-France Bilateral Symposium}

\author{
ADALBERTO LUIS VAL ${ }^{1 *}$ and VIVALDO DE MOURA NETO ${ }^{2,3 *}$ \\ ${ }^{1}$ Instituto Nacional de Pesquisas da Amazônia - INPA/MCTIC, Laboratory of Ecophysiology and Molecular Evolution, Ave. \\ Andre Araujo, 2936, 69080-971 Manaus, AM, Brazil \\ ${ }^{2}$ Universidade Federal do Rio de Janeiro, Departamento de Anatomia, Instituto de Ciências Biomédicas, Av. Pau Brasil, s/n, \\ Cidade Universitária, 22905-900 Rio de Janeiro, RJ, Brazil \\ ${ }^{3}$ Instituto Estadual do Cérebro Paulo Niemeyer, Secretaria de Estado de Saúde do Estado do Rio \\ de Janeiro, Rua do Resende, 156, Centro, 20230-024 Rio de Janeiro, RJ, Brazil
}

How to cite: VAL AL AND MOURA NETO V. 2019. Biodiversity: Brazil-France Bilateral Symposium. An Acad Bras Cienc 91: e20190867. DOI 10.1590/0001-3765201920190867.

The word "biodiversity" has such a wide range of meanings that in many cases we need more thorough explanations and, not infrequently, analyses of events so that experts can explain what they are doing to understand the so-called "biodiversity" of a place. When we apply this challenge to the Amazon, we face an unparalleled problem with making explicit the scope and dimension of biodiversity. If the challenge is extended to the oceans, another biological Eldorado, the situation assumes dimensions that we cannot define with a single word. If we consider the different levels of biological organization, such as behavior, morphology, physiology, biochemistry, genetics, among others, biodiversity expands to infinite contours, such as life itself. Despite this range of meanings, the term "biological diversity" only appeared in 1968, and only gained visibility and entered the vocabulary of scientists and biologists in 1980, when the wellknown American biologist Thomas Lovejoy used the term "biodiversity" for the first time (Soulé and Wilcox 1980).

Always impressed with the biodiversity in Brazil, the presidents of the Brazilian and French Academies of Sciences agreed to organize a bilateral symposium to discuss biodiversity studies carried out by scientists from Amazon countries and France, as a means of stimulating technical-scientific cooperation, which is necessary, though not sufficient, to understand the multiple shades of biodiversity. Manaus was chosen for the first event. Subsequent iterations of these symposia are to alternate between the two countries. The present volume of the Annals of the Brazilian Academy of Sciences contains articles referring to selected lectures that were presented at the bilateral symposium in Manaus.

\footnotetext{
*Coeditors

Adalberto Luis Val

dalval.inpa@gmail.com

ORCid https://orcid.org/0000-0002-3823-3868

Vivaldo Moura Neto

vivaldomouraneto@gmail.com

ORCid http://orcid.org/0000-0002-6266-043X
} 
The bilateral Brazil-France symposium on biodiversity was a fascinating journey through fragments of biodiversity. It became evident what we do not know and how limited our knowledge is. The need for cooperation has been obvious, and Brazil and France have been partners since time immemorial in the study of biodiversity, particularly in the Amazon Biome. But the journey must go on. We know about only a small part of the organisms that share this planet with us. Many of these organisms have no name and are not known to science; others may have names, but their basic biology is unknown; and still others have great potential to improve human quality of life but lack in-depth studies of their metabolic characteristics. We are convinced that biodiversity is, in every corner of the world, a gold mine to be explored, because a tiny part of what we know has already contributed new products and processes that allow us to lead better lives, as well as representing security for life (Val 2019).

This event has highlighted many of the threats to the planet's biodiversity: water pollution by metals; eutrophication of water bodies around human settlements; water contamination with antibiotics, analgesics, antidepressants, contraceptives, crude oil along its derivatives, polycyclic aromatic compounds, and microplastics; physical interference in the environment without proper safeguards; and deforestation, among others. However, none of these compares to the dangers posed by the ongoing climate change. Many species already live close to the limits of their biological tolerances and are severely threatened (Campos et al. 2018). It is necessary to take action to preserve these lives in their multiple dimensions.

Finally, this symposium made it clear, once again, that education, science and technology are fundamental to enable us to cohabit with the planet. Without education there is no conscious society, and without science we cannot see the world as it really is.

NOTE: The event would not have been possible without the support of the Federal University of Amazonas, the Brazilian Academy of Sciences and the French Academy of Sciences. Special thanks to Prof. Alexander Kellner, Editor-In-Chief of the Annals of the Brazilian Academy of Sciences.

\section{REFERENCES}

CAMPOS DF, VAL AL AND ALMEIDA-VAL VMF. 2018. The influence of lifestyle and swimming behavior on metabolic rate and thermal tolerance of twelve Amazon forest stream fish species. J Therm Biol 7: 148-154.

SOULÉ ME AND WILCOX BA. 1980. Conservation Biology: An Evolutionary-Ecological Perspective. Sunderland, Massachusetts: Sinauer Associates.

VAL AL. 2019. Conservação da biota aquática da Amazônia. Revista de Estudios Brasileños 6(11): 79-89. 